\title{
Correction to: Trade in Virtual Water: Do Property Rights Matter?
}

\author{
Ankai Xu ${ }^{1}$
}

Published online: 19 April 2018

(C) Springer Science+Business Media B.V., part of Springer Nature 2018

\section{Correction to: Water Resour Manage.} https://doi.org/10.1007/s11269-018-1941-5

Due to an oversight, Figure $2 \mathrm{a}$ was incorrectly captured in the original publication. The correct Figure 2a image is shown below.

The online version of the original article can be found at https://doi.org/10.1007/s11269-018-1941-5

Ankai Xu

ankai.xu@graduateinstitute.ch

1 World Trade Organization, Rue de Lausanne 154, CH 1211 Geneva 21, Switzerland 
(a)
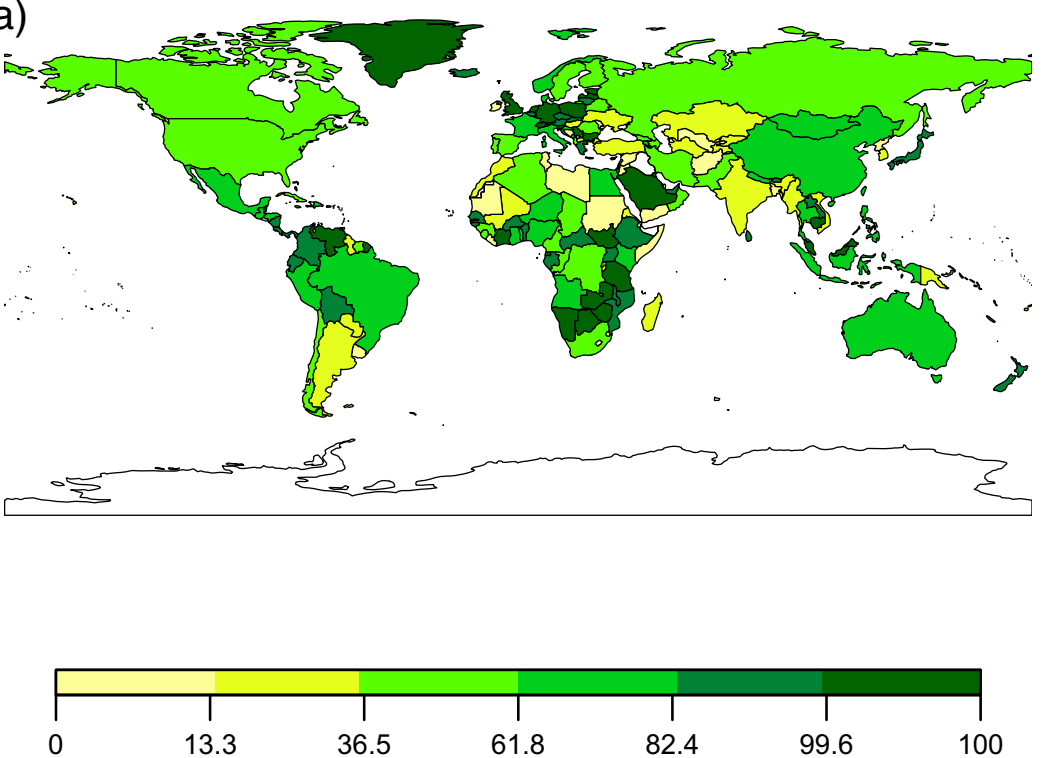

(b)

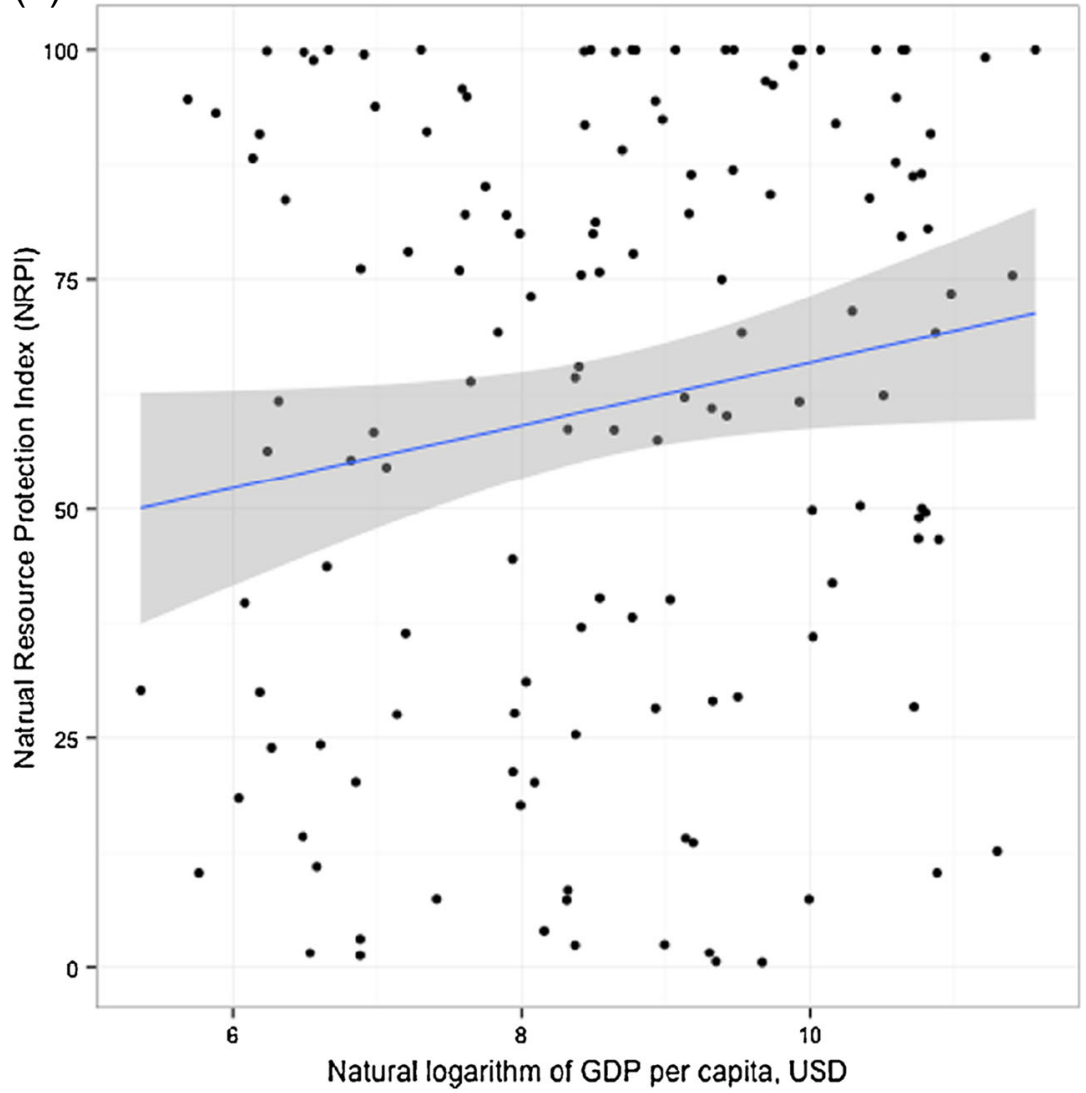

